\title{
Seedling growth and fall armyworm feeding preference influenced by dhurrin production in sorghum
}

\author{
Shelby M. Gruss ${ }^{1} \cdot$ Manoj Ghaste $^{2,3}\left[\right.$ ] Joshua R. Widhalm ${ }^{2,3}\left(\mathbb{D} \cdot\right.$ Mitchell R. Tuinstra $^{1}(\mathbb{C}$
}

Received: 25 June 2021 / Accepted: 1 December 2021 / Published online: 9 January 2022

(c) The Author(s) 2022

\begin{abstract}
Cyanogenic glucosides (CGs) play a key role in host-plant defense to insect feeding; however, the metabolic tradeoffs between synthesis of CGs and plant growth are not well understood. In this study, genetic mutants coupled with nondestructive phenotyping techniques were used to study the impact of the CG dhurrin on fall armyworm [Spodoptera frugiperda (J.E. Smith)] (FAW) feeding and plant growth in sorghum [Sorghum bicolor (L.) Moench]. A genetic mutation in CYP79A1 gene that disrupts dhurrin biosynthesis was used to develop sets of near-isogenic lines (NILs) with contrasting dhurrin contents in the Tx623 bmr6 genetic background. The NILs were evaluated for differences in plant growth and FAW feeding damage in replicated greenhouse and field trials. Greenhouse studies showed that dhurrin-free Tx623 bmr6 cyp $79 a 1$ plants grew more quickly than wild-type plants but were more susceptible to insect feeding based on changes in green plant area (GPA), total leaf area, and total dry weight over time. The NILs exhibited similar patterns of growth in field trials with significant differences in leaf area and dry weight of dhurrin-free plants between the infested and non-infested treatments. Taken together, these studies reveal a significant metabolic tradeoff between CG biosynthesis and plant growth in sorghum seedlings. Disruption of dhurrin biosynthesis produces plants with higher growth rates than wild-type plants but these plants have greater susceptibility to FAW feeding.
\end{abstract}

\section{Introduction}

Plants produce many different types of metabolites that can deter insect feeding (Tattersall et al. 2001; Wittstock and Gershenzon 2002) including cyanogenic glucosides (CG). CGs are a family of compounds found in over 2500 plant species (Jones 1998; Conn 1981; Gleadow and Woodrow 2002; Gleadow and Møller 2014), including sorghum, bitter almond (Hosël and Conn 1982), and cassava, and are thought to play key roles in deterring insect feeding (Gleadow and Woodrow 2002). CGs contribute to host-plant resistance to

Communicated by Emma Mace.

Mitchell R. Tuinstra

drmitch@purdue.edu

1 Department of Agronomy, Purdue University, West Lafayette, IN 47907, USA

2 Department of Horticulture and Landscape Architecture and Center for Plant Biology, Purdue University, West Lafayette, IN 47907, USA

3 Center for Plant Biology, Purdue University, West Lafayette, IN 47907, USA insects by releasing hydrogen cyanide ( $\mathrm{HCN})$ when the plant tissues are disrupted by feeding insects (Zagrobelny et al. 2004). HCN inhibits respiration and the utilization of oxygen (Way 1984; Price 1985). HCN also has a bitter taste (Arrázola et al. 2012) that is suspected to deter herbivory leading to the deterrence of feeding in some insects (Gleadow and Møller 2014).

Feeding deterrence can vary in many ways (Gleadow and Woodrow 2002). One of the key factors controlling deterrence is based on the amount of CGs within the plant tissues with higher concentrations leading to greater deterrence, as shown in a study of Japanese beetle feeding in 24 Prunus species (Patton et al. 1997). Alternate food sources can also influence feeding patterns as insects will generally avoid feeding on plant tissues with high concentrations of CGs if an alternative food source is available (Gleadow and Møller 2014). Bernays et al. (1977) showed that early instars of Zonocerua variegatus would feed on cyanogenic cassava if there were no other choices, but feeding was deterred if another food source was available. The ability of the plant to release $\mathrm{HCN}$ is an additional factor that influences insect deterrence. Krothapalli et al. (2013) demonstrated that the $\beta$-glucosidase that catalyzes rapid $\mathrm{HCN}$ release in sorghum, 
dhurrinase2, played a role in insect feeding deterrence, even in the presence of wild-type levels of CG accumulation. Feeding style also influences the role of CGs in host-plant resistance. Tissue disruption is generally required for $\mathrm{HCN}$ release. CGs generally have little to no effect on aphids that feed by injecting the stylet through the apoplast of the plant to the phloem, minimizing plant tissue damage (Zhu-Salzman 2004; Gleadow and Møller 2014). The relationship of the insect with the plant can also influence the role of CGs on insect feeding. Opportunistic herbivores may be deterred by cyanogenic plants (Cooper and Swain 1976), while specialists are not deterred because these insects may have evolved tolerance to the CG or have the ability to sequester the CG for defense (Zagrobelny et al. 2004).

Dhurrin is the principle CG produced in sorghum. Sorghum plants contain the highest concentrations of dhurrin during early growth stages and within the youngest plant tissues. Dhurrin concentrations peak within the first few days after germination, and then concentrations decline over time (Busk and Moller 2002; Halkier and Moller 1989). Dhurrin concentrations can increase in older plant tissues in response to environmental factors such as extreme drought, over fertilization, and frost stress (Harms and Tucker 1973; Rosati et al. 2019).

Genetic studies have demonstrated that dhurrin contributes to the deterrence of insect feeding in plants. Tattersall et al. (2001) transformed the biosynthetic pathway for dhurrin into Arabidopsis and showed increased resistance to Phyllotreta nemorum, flea beetle. Krothapalli et al. (2013) used chemical mutagenesis to create a knockout of dhurrinase 2 , the $\beta$-glucosidase that catalyzes the release of HCN from dhurrin and showed increased feeding by fall armyworm (FAW). Other mutations that disrupt dhurrin biosynthesis have also been identified (Blomstedt et al. 2012; Tuinstra et al. 2016). These mutations could increase the safety of sorghum forages by reducing the risk of HCN toxicity, but more work is needed to quantify the impact these mutations have on insect feeding and their implications for primary and secondary metabolism.

Lepidoptera insects and other species that did not evolve as a pest of sorghum are good subjects to study the role of dhurrin in deterrence of feeding (Pentzold et al. 2015). Lepidoptera species have chewing mouthparts that cause the breakdown of dhurrin and release of HCN. FAWs have a wide feeding distribution throughout North and South America (Sparks 1979) and currently are emerging as a significant new pest in Africa (Goergen et al. 2016) and Asia (Chormule et al. 2019), infesting over 80 plant species, including cotton, millet, corn, and sorghum (Day et al. 2017). The distribution and wide range of hosts make FAW a significant pest.

Analyses of host-plant resistance and insect feeding generally rely on destructive methods (Krothapalli et al. 2013;
Tattersall et al. 2001) or a ranking system (Diawara et al. 1990) to quantify differences among plant samples. Destructive sampling can be a challenge because each sample provides insight into a single time point, and many samples are required to develop an understanding of changes in feeding preference over time. Alternatively, the ranking scale can be used to assess feeding damage over time, but these measures are subjective and can lead to variation based on the individual ranking the samples. New methods are needed to quickly and accurately phenotype insect feeding characteristics. Nondestructive imaging techniques have shown promise in efforts to classify plant phenotypes in an efficient manner with lower overall costs, time, and labor (Araus and Cairns 2014; Hairmansis et al. 2014). Image-based phenotyping systems have been used to calculate relative growth rate of sorghum based on changes over time (Neilson et al. 2015) and could be beneficial in quantifying feeding damage based on the changes in plant biomass from insect herbivory.

Dhurrin accumulation and turnover play key roles in primary and secondary metabolism by influencing sorghum responses to insect feeding and adaptation to abiotic stresses. In this study, genetic mutants coupled with high-throughput image-based phenotyping techniques were used to explore tradeoffs for manipulating dhurrin metabolism in sorghum under conditions of FAW infestations. Specific objectives included to (1) evaluate the sensitivity of nondestructive plant imaging techniques for quantifying feeding damage in sorghum and to (2) evaluate NILs contrasting for dhurrin accumulation for differences in plant growth and feeding damage following infestation by FAW in greenhouse and field trials. The NILs were selected for variation in cyp79al mutation and the brown midrib ( $b m r)$ trait. Both traits have value in sorghum when used as a forage. The bmr trait decreases lignin content, thereby increasing digestibility (Porter et al. 1978). CYP79A1 is a cytochrome P450 that catalyzes the conversion of L-tyrosine to $p$-hydroxyphenylacetaldoxime in the biosynthesis of dhurrin (Halkier et al. 1991); thus, the cyp79al trait decreases the risk of HCN toxicity.

\section{Materials and methods}

\section{Insects}

Fall armyworm (FAW) was obtained from Benzon Research (Carlisle, PA) at the 2nd/3rd instar for the calibration experiments and at the 1st instar stage for all subsequent greenhouse and field trials. 


\section{Sorghum genotypes}

Three sorghum genotypes were evaluated in the first set of calibration studies: (1) Tx623 (Miller 1978), (2) SbEMS932 dhr2-1 (mutation in the dhurrinase2 enzyme described by Krothapalli et al. (2013)), and (3) SbEMS2447 cyp79al (C493Y mutation in the CYP79A1 enzyme described by Tuinstra et al. (2016)). The mutants were developed in the Tx623 genetic background but exhibited reduced vigor due to genetic load.

NILs Tx623, Tx623 bmr6 (Oliver et al. 2005), and Tx623 bmr6 cyp79al were used in all subsequent experiments. Dhurrin contents of Tx623 and Tx623 bmr6 were determined on seedlings at the third leaf stage through dhurrin extraction and processing through ultra-high performance liquid chromatography (UHPLC) as described below. Dhurrin contents of Tx623 and Tx623 bmr6 were compared using a $T$ test. Tx623 bmr6 cyp79al was developed by crossing and backcrossing (BC1F7) SbEMS2447 cyp79al to Tx623 bmr6 followed by selfing and selection for no HCN production using the Feigl Anger (FA) assay (Feigl and Anger 1966).

\section{Imaging platform and calibration}

An ARIS TopView Phenotyping System (ARIS, Eindhoven, Netherlands) was used in plant imaging studies. ARIS uses seven channels to calculate the green plant area (GPA), hue, saturation, and other factors. The ARIS system calculates the GPA $\left(\mathrm{mm}^{2}\right)$ based on pixel count.

Calibration studies were conducted using Tx623, SbEMS932 dhr2-1, and SbEMS2447 cyp79al. Twenty plants of each genotype were grown to evaluate the use of GPA and changes in GPA over time to quantify insect feeding damage. Sorghum plants were grown in plastic Conetainers (Hummert International, St. Louis, MO) that were $120 \mathrm{~cm}^{2}$ in a cylindrical shape. The Cone-tainers were filled with the propagation mix (Sun-Gro Horticulture, Agawam, MA) with a single plant per container for approximately 3 weeks. After 2 weeks, the plants were fertilized with Miracle-Gro Garden Feeder (The Scott's Company, Marysville, $\mathrm{OH})$ at a rate of $350 \mathrm{ppm}$ of nitrogen, $100 \mathrm{ppm}$ of phosphorous, and $200 \mathrm{ppm}$ of potassium. Each plant was tested for repeatability of GPA measurements by first measuring each sorghum plant then measuring them again after $1 \mathrm{~h}$ keeping the plant orientation consistent from image to image. This was completed on a whole plant basis. Using the same three genotypes, 16 plants of each were imaged for GPA and total leaf area $\left(\mathrm{mm}^{2}\right)$ of each plant was determined by removing all the leaves and leaf tips at the collar, imaging all the leaves using an RGB camera, and processing imagery with Image J software (https://imagej.net/) for comparison with GPA.
GPA measured by ARIS was also compared with total leaf area $\left(\mathrm{mm}^{2}\right)$ and total dry weight $(\mathrm{g})$ of plants with and without FAW feeding using the same three genotypes described above. Twenty-three plants of SbEMS2447 cyp79al and Tx623 at the 4-leaf stage were placed in one rack, twentythree plants of SbEMS2447 cyp79al and SbEMS932 dhr2-1 at the 4-leaf stage were placed in another rack, and sixteen plants of all three genotypes at the 4-leaf stage were placed in the final rack. Each rack was placed into different enclosures and infested with FAW. The enclosures were infested with approximately $150 \mathrm{FAWs}$ at the 2 nd instar stage. The FAWs were starved for $2 \mathrm{~h}$ before infestation. Infestation occurred for $36 \mathrm{~h}$ with ARIS GPA $\left(\mathrm{mm}^{2}\right)$ recorded at 0,12 , 24 , and $36 \mathrm{~h}$ to track changes across time (Fig. 2) and verify ARIS GPA. After $36 \mathrm{~h}$, each plant was harvested and total leaf area was measured by removing all the leaves and leaf tips at their collar, imaged using an RGB camera, and images processed using Image $\mathbf{J}$ software.

This experiment was repeated but with four enclosures: three infested with FAW and one with no insects. Sixteen plants of each genotype were grown to the 4-leaf stage and randomly placed in racks for evaluation with one rack in each of the four enclosures. In addition to imaging comparisons at $36 \mathrm{~h}$, dry weights were determined by drying the plant material in a paper envelope at $60{ }^{\circ} \mathrm{C}$ for 1 week.

\section{Feigl Anger (FA) assay}

The NILs Tx623, Tx623 bmr6, and Tx623 bmr6 cyp79al were compared for insect susceptibility in greenhouse and the field trials. The phenotypes of plants in each experiment were measured using a FA assay (Feigl and Anger 1966) to verify expected differences in HCN release. The FA assay was conducted by harvesting a $2.5 \mathrm{~cm}$ section of the topcollared leaf of a seedling at the 3-leaf stage. The sample was placed in a 96 well plate and frozen in a $-80^{\circ} \mathrm{C}$ freezer overnight. The next day the plate was moved to room temperature and the plate was covered with the FA paper and covered with the lid to form a tight seal between the paper and plate. After 15-30 min, the FA paper was removed and photographed to capture differences in blue coloring representing $\mathrm{HCN}$ release.

\section{Dhurrin extraction}

The top collared leaf of the plant was weighed for fresh weight and instantly frozen in liquid $\mathrm{N}$. The frozen tissue sample was ground in liquid $\mathrm{N}$. The ground plant samples were extracted using 1:1 MeOH: $\mathrm{H}_{2} \mathrm{O}$ containing $0.05 \mathrm{mg} /$ $\mathrm{mL} p$-hydroxybenzaldehyde as an internal standard. The extraction was performed by adding $3 \mathrm{ml}$ of extraction solvent to each $5 \mathrm{~mL}$ tube containing ground sample tissue. Tubes were incubated in a water bath at $75^{\circ} \mathrm{C}$ for $15 \mathrm{~min}$, 
then removed, vortexed, and placed at $4{ }^{\circ} \mathrm{C}$ for $16-24 \mathrm{~h}$. The next day, the tubes were vortexed and centrifuged and $1 \mathrm{~mL}$ of extract was collected and filtered through a $0.2 \mu \mathrm{m}$ filter into a labeled $1.5 \mathrm{~mL}$ microcentrifuge tube. $200 \mu \mathrm{L}$ of the filtered extract was transferred into vials for ultra-high performance liquid chromatography (UHPLC) analysis.

\section{UHPLC analysis}

UHPLC analysis was performed by using a 1290 Infinity II UHPLC system with a diode array detector (Agilent Technologies, Santa Clara, CA, USA). The separation of compounds was achieved on the Zorbax SB-C18 column $(1.8 \mu \mathrm{m}, 2.1 \times 50 \mathrm{~mm}$; Agilent $)$ with column temperature maintained at $30{ }^{\circ} \mathrm{C}$. Water (A) and $\mathrm{ACN}$ (B) was used as mobile phase solvents with $0.1 \%$ formic acid $(v / v)$ at a flow rate of $0.3 \mathrm{~mL} \mathrm{~min}^{-1}$. The solvent gradient program was set as described in Table 1 with a total run time of $7 \mathrm{~min}$. $5 \mu \mathrm{L}$ of injection volume was used both for samples and standards.

Table 1 UHPLC solvent gradient program

\begin{tabular}{llll}
\hline Time $(\mathrm{min})$ & $A(\%)$ & $B(\%)$ & Flow $(\mathrm{ml} / \mathrm{min})$ \\
\hline 0.00 & 90.00 & 10.00 & 0.300 \\
1.00 & 90.00 & 10.00 & 0.300 \\
3.00 & 75.00 & 25.00 & 0.300 \\
4.00 & 75.00 & 25.00 & 0.300 \\
5.00 & 5.00 & 95.00 & 0.300 \\
6.00 & 5.00 & 95.00 & 0.300 \\
7.00 & 90 & 10.00 & 0.300 \\
\hline
\end{tabular}

Dhurrin and $p$-hydroxybenzaldehyde were eluted at 1.11 and $2.65 \mathrm{~min}$, respectively (Fig. 1), absorbance for both compounds were recorded at $232 \mathrm{~nm}$. Dhurrin quantitation was performed by analyzing the linear range of 0.0025 , $0.0050,0.0100,0.0250,0.0500 \mathrm{mg} / \mathrm{mL}$ standards each containing $0.05 \mathrm{mg} / \mathrm{mL} p$-hydroxybenzaldehyde as an internal standard. Instrument operation and data analyses were performed using OpenLAB CDS ChemStation software version C.01.09.

\section{Greenhouse trials}

A greenhouse study was designed to compare insect feeding in Tx623, Tx623 bmr6, and Tx623 bmr6 cyp79a1. Two NILs differ for the bmr6 trait, and two NILs differ for the cyp79al trait allowing tests of both traits on insect susceptibility. The experiment was conducted using a randomized complete block design with each genotype represented by 16 plants in each of four enclosures using plants of similar size at the 3-leaf stage. One enclosure was not infested with FAW and the other three insect treated enclosures were infested with approximately 150 FAWs at the 1st instar stage to avoid any increased tolerance in the insects due to age. The duration of feeding was increased to $96 \mathrm{~h}$ compared to the $36 \mathrm{~h}$ in the calibration study to provide an opportunity for significant insect damage to occur in each enclosure with ARIS GPA taken every $24 \mathrm{~h}$. After $96 \mathrm{~h}$, dry weight (g) of each plant was determined as described in the calibration studies.

\section{Field trials}

Field trials were conducted in 2019 and 2020 using the NILs Tx623, Tx623 bmr6, and Tx623 bmr6 cyp79al. The

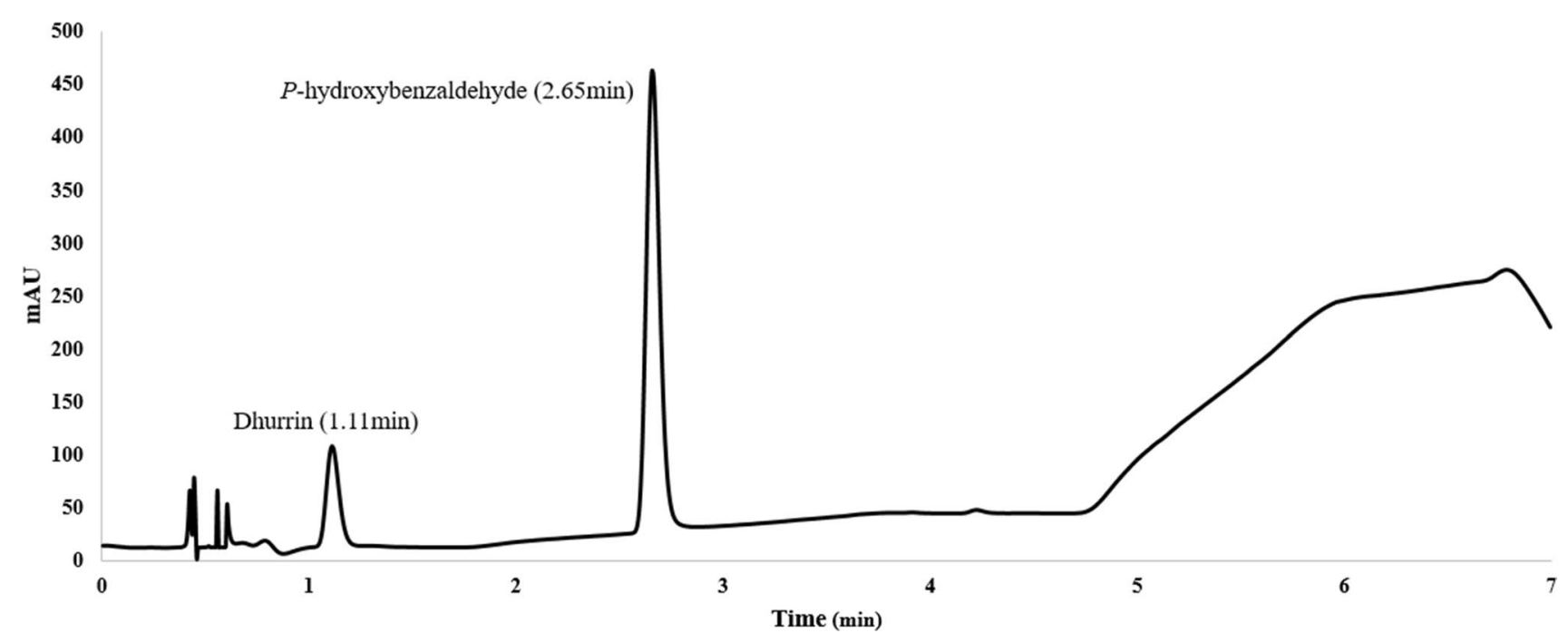

Fig. 1 DAD chromatogram $(232 \mathrm{~nm})$ of dhurrin $(1.11 \mathrm{~min})$ and p-hydroxybenzaldehyde $(2.65)$ at the concentrations of $0.01 \mathrm{and} 0.05 \mathrm{mg} / \mathrm{mL}$, respectively 
plots were overplanted and thinned to 85,000 plants $^{-1}$ in $0.76 \times 3.1 \mathrm{~m}$ plots to plants of similar size and leaf stage with five replications in 2019 and six replications in 2020 in a split plot design with FAW infestation as whole plots and genotype as subplots. Each subplot was surrounded by a barrier using lawn edging (Master Mark, Paynesville, MN) to limit FAW movement within the subplots. Two rounds of this experiment were completed in the summer of 2019 in June and July, and the third round was completed in June 2020. All three experiments were planted at the Purdue Agronomy Center for Research and Education. In 2019, plants were infested with FAW at the 3- to 4-leaf stage using a bazooka applicator (Wiseman and Widstrom, 1980) with 4-5 insects per plant at the 1st instar stage for round 1 and 6-7 insects per plant for round 2. Two replications were harvested at 5 days and three replications harvested at 10 days. Twenty plants per plot were measured for dry weight (g). A subsample of four plants was measured for total leaf area $\left(\mathrm{cm}^{2}\right)$ using a LI-3100C Leaf Area Meter (LICOR Biosciences, Lincoln, NE). A similar experiment was conducted in 2020 with six replications. Plants at the 3-leaf to 4-leaf stage were treated with FAW at the 1st instar stage on June 23, 2020 using a bazooka applicator at a rate of 4-5 insects per plants. Plots were harvested on day 12 with a longer infestation time due to cool weather and slow feeding rates. Ten plants were harvested per plot and measured for total dry weight $(\mathrm{g})$ and four plants were measured for total leaf area $\left(\mathrm{cm}^{2}\right)$.

\section{Statistical analysis}

Regression analyses were used to compare GPA to total leaf area $\left(\mathrm{mm}^{2}\right)$ and dry weight $(\mathrm{g})$ over time. Outliers for each dataset was detected using boxplots. The boxplots were designed to describe the dependent variable; green plant area, dry weight, or total leaf area, based on the entry, treatments, and hours if captured. Outliers were removed from the dataset (Supplementary information, Fig. S1 and Fig. S2).

A mixed effects model was used to determine the effects of the insect treatments on the different genotypes in the greenhouse experiments. Entry, Treatment, Hours, and their interactions were treated as fixed effects and replications nested within hours were treated as random effects. Least square means were compared using Tukey's test with Kenward-Rogers degrees of freedom.

A mixed effects model was also used to determine the effects of the insect treatments on the different genotypes in the field experiments. Fixed effects were entry, treatment, days, and interactions for 2019, while days were not a factor in 2020. Replication was evaluated as a random effect. Each experiment was analyzed separately and in a combined analysis. Least square means were compared using Tukey's test with Kenward-Rogers degrees of freedom. Dry weights were transformed with a square root transformation to fit a normal distribution. The transformed data were used to screen for outliers, build the mixed effects model, and for Tukey's test.

\section{Results}

\section{Nondestructive plant imaging to quantify insect feeding damage}

Calibration studies were conducted to determine the repeatability of green plant area (GPA) measurements from the ARIS TopView Phenotyping System. Figure 2 shows the mask created to calculate GPA across time and insect feeding. The average GPA measurements for the first set of measurements was $3155.6 \mathrm{~mm}^{2}$, and the second set of measurements average was $3165.2 \mathrm{~mm}^{2}$. Repeated measures were compared by regression with an $R^{2}$ of 0.98 (Fig. 3a). Comparisons of GPA with total leaf area measured by destructive sampling and fall armyworm (FAW) feeding showed an $R^{2}$ of 0.86 (Fig. 3b). Comparisons of the GPA with total dry weight showed similar results with an $R^{2}$ of 0.77 . Pearson's Correlation showed a correlation of 0.93 compared to total leaf area and a correlation of 0.88 with dry weight (Fig. 3c). The correlation between the GPA and the plant fresh weight was not as high with an $R^{2}$ of 0.61 (not shown).

\section{Dhurrin production and $\mathrm{HCN}$ release}

Analyses of dhurrin content of the NILs Tx623 (5.2 $\left.\mathrm{mg} \mathrm{g}^{-1}\right)$ and Tx623 bmr6 $\left(6.25 \mathrm{mg} \mathrm{g}^{-1}\right)$ at the 3-leaf stage indicated no significant differences among lines. Analyses of HCN release before each experiment showed that Tx623 and

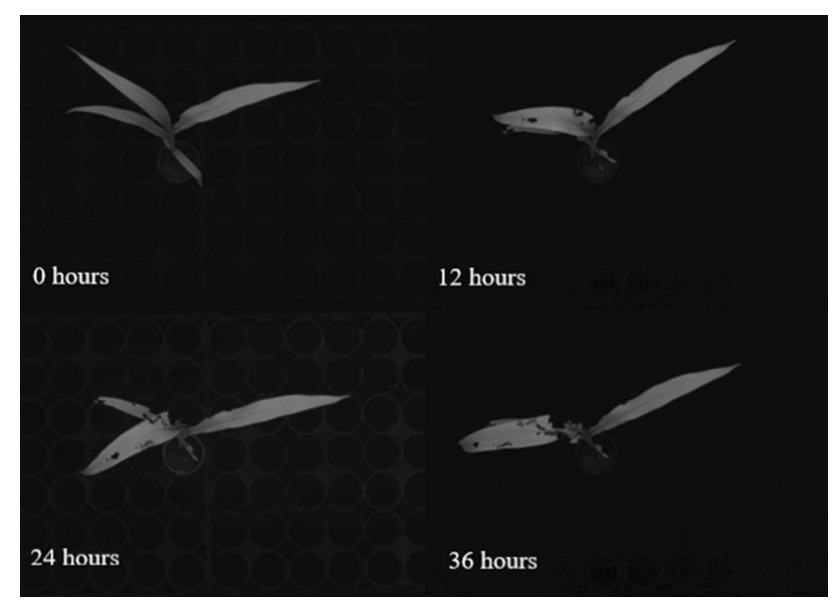

Fig. 2 Infested sorghum plant imaged at 0, 12, 24, and $36 \mathrm{~h}$ after FAW infestation 
Fig. 3 Linear regression models comparing a consistency of GPA across measurements, $\mathbf{b}$ GPA $\left(\mathrm{mm}^{2}\right)$ to total leaf area $\left(\mathrm{mm}^{2}\right)$ from processing with ImageJ, and $\mathbf{c}$ GPA $\left(\mathrm{mm}^{2}\right)$ to total dry weight $(\mathrm{g})$
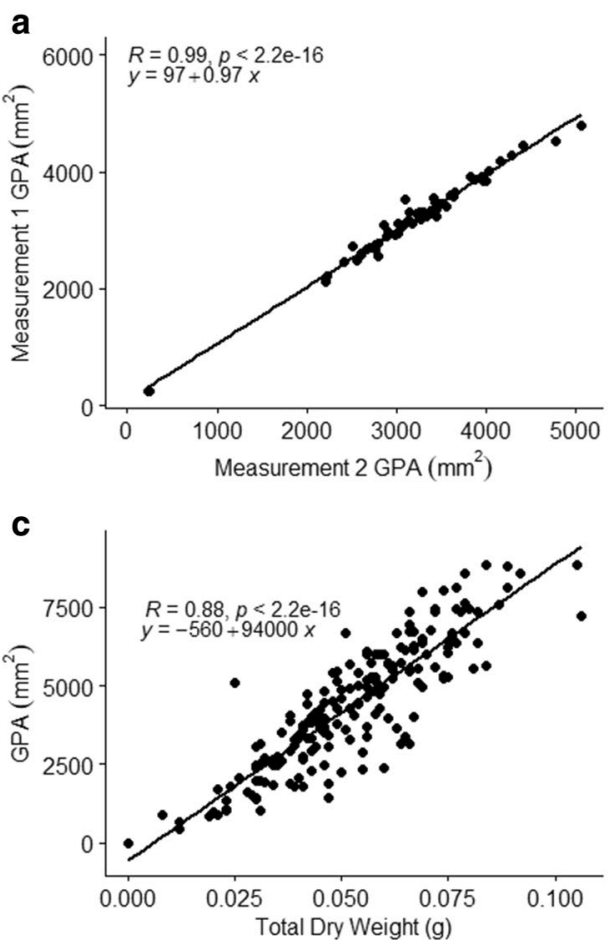

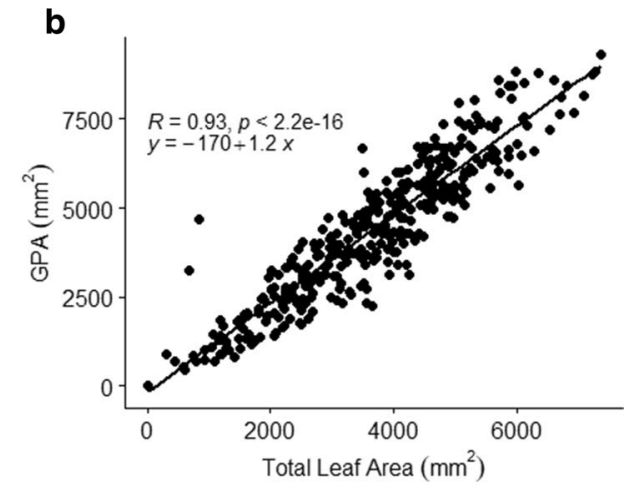

Tx623 bmr6 released HCN within 15 min after thawing (Fig. 4). Tx623 bmr6 cyp79al did not show any release of $\mathrm{HCN}$ by remaining white (Fig. 4).

\section{Dhurrin biosynthesis influences sorghum growth and fall armyworm feeding preference}

NILs of Tx623 contrasting for cyp79al and bmr6 mutations were compared for plant growth and susceptibility to FAW feeding under infested and non-infested conditions in greenhouse trials. Under non-infested conditions, the GPA for each of the three NILs increased over time as the plants maintained rapid growth (Fig. 5a). The dhurrin-free Tx623 bmr6 cyp79al plants exhibited significantly higher GPA (Fig. 5a) and dry weight (Fig. 5b) than Tx623 and Tx623 bmr6 plants at $96 \mathrm{~h}$ under non-infested conditions. Conversely, GPA remained steady or decreased over time in the sorghum NILs infested with FAW (Fig. 5a). The GPA of the infested Tx623 bmr6 cyp79al plants decreased over time as the feeding trial progressed (Fig. 5a). Further analyses of GPA indicated that the insects began to devour enough plant material to measure a difference in plant area for Tx623 bmr6 cyp 79al between 48 and $72 \mathrm{~h}$ while Tx623 and Tx623 bmr6 did not exhibit a difference until 72 and $96 \mathrm{~h}$ (Fig. 5a). The Tx623 bmr6 cyp79al plants exhibited the largest difference in GPA (Fig. 5a) and dry weight (Fig. 5b) between the infested and non-infested treatments at $96 \mathrm{~h}$ demonstrating feeding preference for dhurrin-free plants.

The sorghum NILs were also evaluated for variation in leaf area and dry weight under FAW infested and noninfested conditions in field trials conducted in 2019 and 2020. The FAW treatment effects were significant in each study with infested plants exhibiting similar or lower total leaf areas and dry weights than non-infested plants for each genotype (Table 2). Genotype by treatment interaction effects was observed for total leaf area in one study in 2019 and for dry weight in both trials conducted in 2019 (Table 2). Tx623 bmr6 cyp79al was the only NIL in the study that
Fig. 4 Feigl Anger (FA) assay comparing the NILs for $\mathrm{HCN}$ (blue) or no $\mathrm{HCN}$ (white) production

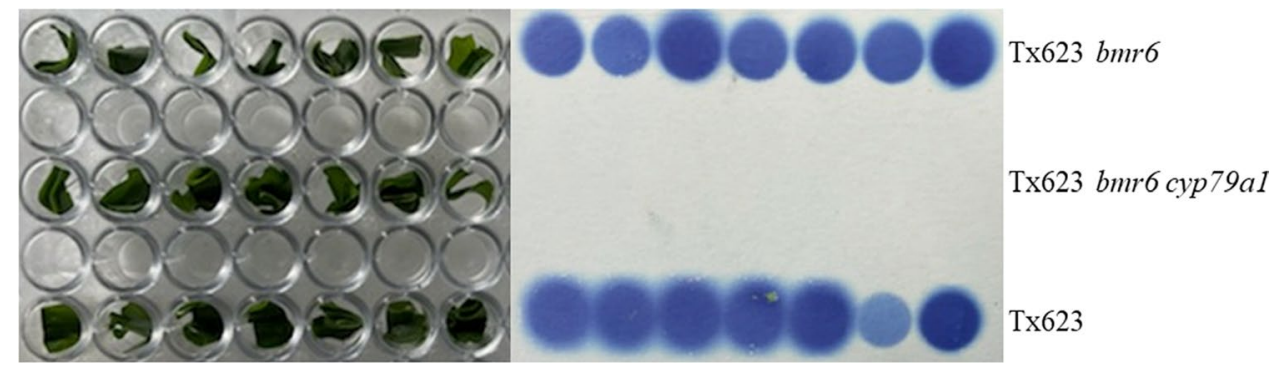


Fig. 5 Effects of the cyp79al and bmr6 mutations on FAW feeding in greenhouse trials of sorghum NILs contrasting in dhurrin production based on a changes in GPA over time after infestation and $\mathbf{b}$ average dry weight at $96 \mathrm{~h}$ with the letters representing Tukey's comparisons across genotypes and treatments. $* * \alpha=0.01, * * * \alpha=0.001$

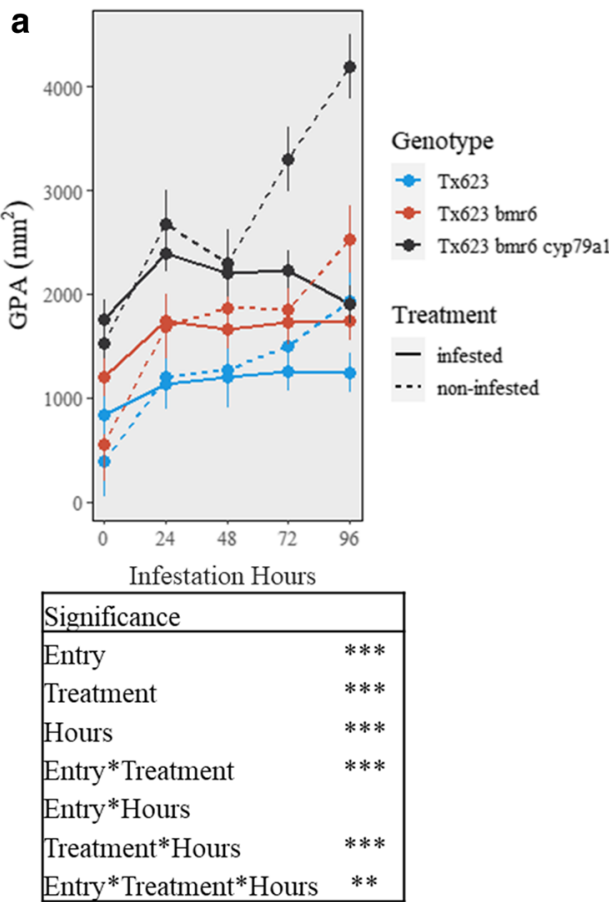

exhibited significant differences in total leaf area and dry weight between infested and non-infested treatments in all three studies (Table 2). These differences demonstrate that more FAW feeding occurred in the dhurrin-free Tx623 bmr6 cyp79al as compared to Tx623 and Tx623 bmr6. Although more susceptible to FAW feeding, the dhurrin-free plants did not exhibit differences in leaf area or dry weight from the wild-type plants in the FAW infested treatments due to increased size of the dhurrin-free plants prior to infestation.

\section{Discussion}

Many studies have demonstrated the value of image-based sorghum phenotyping technologies for assessment of plant growth and development (Neilson et al. 2015; Batz et al. 2016; Thapa et al. 2018; Masjedi et al. 2020). In this study, the ARIS phenotyping platform was shown to be useful for collecting nondestructive measurements of green plant area (GPA) in sorghum. Estimates of GPA were consistent over time and compared favorably with estimates of total leaf area calculated using ImageJ software and total dry weight for insect feeding damage. Unlike destructive measurements of insect feeding based on changes in dry weight and leaf area, the ARIS platform was useful for taking nondestructive measurements of the same plant over a time when the insects were feeding. The platform was able to detect a decrease in leaf area compared to the non-infested plants due to feeding within and along the leaf margins. This image-based technique also avoids challenges with subjective ratings, provides for measurements at multiple time points, and is quick and easy to use. The opportunity for taking multiple readings per plant was particularly useful for measuring plant-insect interactions among genotypes. This provided unique insights into the feeding patterns of the insects throughout the infestation period.

Fall armyworm (FAW) generally is a pest of sorghum at later stages of development when the whorl is developed or the paniclse of sorghum plants have emerged (Diawara et al. 1990). In this study, sorghum plants were infested at earlier stages of development to study FAW feeding preference when dhurrin content is generally higher than observed at later stages of development (Burke et al. 2013). Dhurrin content can vary depending on environmental stresses including drought (O'Donnell et al. 2013; Rosati et al. 2019), frost (Gleadow and Møller 2014; Strickland et al. 2017), and overfertilization (Busk and Moller 2002). Wiseman and Gourley (1982) showed that seedling plants have consistent patterns of resistance at the whorl stage and can be used to study patterns of susceptibility and resistance to FAW feeding. Comparisons of infested and non-infested plants demonstrated significant differences in GPA and dry weight with infested plants consistently smaller than the non-infested plants in each round of the experiment. Interactions between genotypes and infestation treatments provided evidence for differences in susceptibility to FAW feeding. FAW feeding studies in greenhouse trials produced plant damage more quickly than in field studies. This could be due to a more consistent and favorable environment for plant and insect development within the greenhouse. Rain, wind, cool nights, 
Table 2 Variation in leaf area and dry weight of sorghum NILs contrasting for brown midrib (bmr6) and dhurrin biosynthesis (cyp79al) mutations under fall army worm (FAW) infested and non-infested conditions in field trials in 2019 and 2020

\begin{tabular}{|c|c|c|c|c|c|c|c|}
\hline \multirow[t]{2}{*}{ Entry } & \multirow[t]{2}{*}{ FAW treatment } & \multicolumn{6}{|c|}{ Total leaf area $\left(\mathrm{cm}^{2}\right)$} \\
\hline & & \multicolumn{2}{|l|}{$2019-1^{\mathrm{a}}$} & \multicolumn{2}{|l|}{ 2019-2 } & \multicolumn{2}{|l|}{2020} \\
\hline Тх623 bmr6 cyp79al & No & 251 & $\mathrm{a}$ & 568 & $\mathrm{a}$ & 1069 & $\mathrm{a}$ \\
\hline Tx623 bmr6 & & 108 & $\mathrm{~b}$ & 501 & $a b$ & 995 & $a b$ \\
\hline Тх623 & & 241 & $a b$ & 467 & $a b$ & 973 & $a b c$ \\
\hline Тх623 bmr6 cyp79a1 & Yes & 149 & $\mathrm{~b}$ & 366 & $\mathrm{bc}$ & 887 & $\mathrm{bc}$ \\
\hline Тх623 bmr6 & & 90 & $\mathrm{~b}$ & 368 & $\mathrm{bc}$ & 834 & $\mathrm{bc}$ \\
\hline Тх623 & & 188 & $a b$ & 543 & $a b$ & 785 & $\mathrm{c}$ \\
\hline \multirow[t]{3}{*}{ Significance $^{\mathrm{b}}$} & Entry & \multicolumn{6}{|l|}{$* * *$} \\
\hline & Treatment & \multirow{2}{*}{\multicolumn{2}{|c|}{$* *$}} & \multicolumn{2}{|l|}{$*$} & \multicolumn{2}{|l|}{$* * *$} \\
\hline & Entry* Treatment & & & $* *$ & & & \\
\hline \multirow[t]{2}{*}{ Entry } & FAW treatment & \multicolumn{6}{|c|}{ Total dry weight $\left(\mathrm{g}_{\text {plant }}{ }^{-1}\right)$} \\
\hline & & \multicolumn{2}{|l|}{ 2019-1 } & \multicolumn{2}{|l|}{ 2019-2 } & \multicolumn{2}{|l|}{2020} \\
\hline Тх623 bmr6 cyp79al & No & $1.57^{\mathrm{c}}$ & $\mathrm{a}$ & 3.26 & $\mathrm{a}$ & 9.93 & $\mathrm{a}$ \\
\hline Тх623 bmr6 & & 0.84 & $\mathrm{~b}$ & 2.59 & $\mathrm{~b}$ & 9.93 & $a b$ \\
\hline Tx623 & & 1.58 & $\mathrm{a}$ & 2.6 & $\mathrm{~b}$ & 9.12 & $a b c$ \\
\hline Тх623 bmr6 cyp79al & Yes & 0.99 & $\mathrm{bc}$ & 2.35 & $\mathrm{bc}$ & 8.31 & $\mathrm{c}$ \\
\hline Tx623 bmr6 & & 0.6 & $\mathrm{~b}$ & 2.18 & $\mathrm{bc}$ & 8.7 & $a b c$ \\
\hline Tх623 & & 1.12 & $\mathrm{bc}$ & 3.02 & $a b$ & 9.34 & $a b c$ \\
\hline \multirow[t]{3}{*}{ Significance } & Entry & $* * *$ & & $* *$ & & & \\
\hline & Treatment & \multirow[t]{2}{*}{$* * *$} & & $* *$ & & \multirow[t]{2}{*}{$* * *$} & \\
\hline & Entry* Treatment & & & \multicolumn{2}{|l|}{$* * *$} & & \\
\hline
\end{tabular}

Differences between values are shown using Tukey's Test. Analyses of variance tests were used to test significance of Entry, Treatment, and Entry x Treatment interactions

${ }^{\mathrm{a}}$ For the 2019 data, the day 5 values are not presented because there were no significant effects

$\mathrm{b} * 0.05, * * 0.01, * * *=0.001$

${ }^{\mathrm{c}}$ All average values are based on the original data

and predators such as birds may have slowed FAW feeding damage in the field studies.

NILs contrasting for bmr6 responded to the FAW feeding in field and greenhouse trials with a pattern of response to FAW infestation similar to studies described by Dowd and Sattler (2015). The wild-type and bmr6 plants had similar dry weights in the infested and non-infested treatments at $96 \mathrm{~h}$. These observations suggest that the plants were growing at a similar rate and with similar FAW feeding over time. NILs contrasting for cyp79al exhibited a different pattern of plant growth and feeding preference. The cyp79al plants generally produced higher GPA and dry weights under noninfested conditions compared to wild-type plants in greenhouse and field trials. This observation suggests that carbon and nitrogen pools otherwise committed to dhurrin biosynthesis may be redirected to support a higher growth rate of vegetative tissues. This differs from what was reported for the totally cyanide deficient mutant 1 (tcdl), that exhibited delayed germination (Montini et al. 2020), reduced growth during early seedling growth (Blomstedt et al. 2012), and altered flowering times (Sohail et al. 2020). The reduced growth during germination in $t c d l$ plants likely highlights importance of recycling dhurrin for germination and early seedling growth (Montini et al. 2020).

While cyp79al and tcdl both lead to mutations in CYP79A1 and loss of dhurrin production, they lead to changes at different residues in the enzyme. The cyp79al mutant contains a C493Y mutation (Tuinstra et al. 2016), while $t c d 1$ bears a P414L mutation (Blomstedt et al. 2012). CYP79A1 catalyzes two N-hydroxylation reactions to afford a highly unstable $N, N$-dihydroxytyrosine intermediate, which is subsequently dehydrated and decarboxylated to form the final CYP79A1 product, (E)-p-hydroxyphenylacetaldoxime (reviewed in Sørensen et al. 2018). It therefore seems reasonable to predict that the C493Y and P414L mutations may have different structural consequences that could lead to the accumulation of different CYP79A1 reaction intermediates that might also contribute to the different phenotypic differences observed in the dhurrin-free $t c d l$ and cyp79al mutants. 
In contrast to non-infested conditions, the growth of cyp79al plants was reduced compared to wild-type plants upon infestation by FAW. The infested cyp $79 a 1$ plants were consistently smaller than the non-infested plants and showed the largest reduction in GPA and dry weight over time following infestation by FAW. This indicated that the wild-type plants were more resistant to insect feeding than dhurrin-free plants. This is consistent with reports of increased insect resistance when introducing dhurrin biosynthesis into Arabidopsis (Tattersall et al. 2001) and greater susceptibility in sorghum plants having reduced capacity to release $\mathrm{HCN}$ due to a genetic mutation in dhurrinase2 (Krothapalli et al. 2013). In both cases, the insect species had chewing mouthparts that are necessary to release HCN during feeding.

Manipulation of dhurrin metabolism may provide a strategy to increase sorghum growth rate when infestations of insects such as FAW are controlled; however, dhurrin metabolism is complex and reported to play a role in nitrogen use efficiency (Neilson et al. 2015; Blomstedt et al. 2018; Rosati et al. 2019) and drought tolerance (Burke et al. 2013; Adeyanju et al. 2016; Hayes et al. 2016; Varoquaux et al. 2019). Follow-up studies are needed to examine the metabolic tradeoffs that influence sorghum germination, productivity, and sustainability with variable nitrogen and water inputs.

\section{Conclusions}

Dhurrin metabolism plays an important role in sorghum resistance to FAW feeding. Given the tremendous flux of carbon and nitrogen through this metabolic hub, dhurrin production also influences plant growth and development. This study demonstrated that a genetic mutation that disrupts dhurrin biosynthesis also positively impacts plant growth and development in non-infested growing conditions. Taken together, these studies revealed a significant metabolic tradeoff between CG biosynthesis and plant growth in sorghum seedlings. These results suggest that it may be possible to manipulate dhurrin metabolism to optimize sorghum productivity in diverse production environments.

Supplementary Information The online version contains supplementary material available at https://doi.org/10.1007/s00122-021-04017-4.

Acknowledgements We thank Andrew Linvill, Eugene Glover, and the Tuinstra Lab for help in collecting data in greenhouse, growth chamber, and field trials. We would also like to acknowledge the Institute for Plant Sciences at Purdue University for support in training and use of the ARIS TopView Phenotyping System.

Author contribution statement SG and MT developed the idea and developed a plan in testing the hypotheses. MT developed the lines used in the study. SG carried out the studies under the supervision of MT. MG and JRW developed the dhurrin extraction and UHPLC-based detection and quantification method. MG analyzed dhurrin content under the supervision of JRW. SG analyzed the data, and all authors discussed the results and conclusions made. SG wrote the first draft of the manuscript and all authors read and edited it. MT acquired funding for the work.

Funding This research was supported by the College of Agriculture, Purdue University and the Sustainable Food, Energy, and Water Systems program funded by National Science Foundation Research Traineeship Award 1735282. This work was also supported by the USDA National Institute of Food and Agriculture Hatch Project Number 177845 to J.R.W.

Data availability Plant growth and development data from the greenhouse and field trials described in this publication are available at the Purdue University Research Repository (PURR) (Gruss and Tuinstra, 2021). The files are designated by location and year with locations shown as greenhouse $(\mathrm{GH})$ or field (WL) then the year the study took place. For example, the GH18_insect_data.xlsx includes data from the greenhouse trials in 2018. Within each file, there may be multiple sheets that define the type of data collected. Data for green plant area collected with the Aris TopView Phenotyping System, total leaf area, fresh weight, and dry weight are organized by plot, genotype, and insect infestation treatment. Temporal data from the greenhouse trials include time (hours) when measurements was taken, the plant number, and insect infestation treatment. More details of each of the data and $\mathrm{R}$ code files are included in the READ_ME file (Gruss and Tuinstra, 2021).

Material availability Seeds of genetic mutants are available for noncommercial research purposes under a material transfer agreement with Purdue University.

\section{Declarations}

Conflict of interest MT is an inventor for a patent on genetic mutations that disrupt dhurrin production in sorghum (Tuinstra et al. 2016).

Ethical approval We declare that none of the manuscript report data was collected from humans or animals and do not involve any human participants or report any health-related outcomes.

Open Access This article is licensed under a Creative Commons Attribution 4.0 International License, which permits use, sharing, adaptation, distribution and reproduction in any medium or format, as long as you give appropriate credit to the original author(s) and the source, provide a link to the Creative Commons licence, and indicate if changes were made. The images or other third party material in this article are included in the article's Creative Commons licence, unless indicated otherwise in a credit line to the material. If material is not included in the article's Creative Commons licence and your intended use is not permitted by statutory regulation or exceeds the permitted use, you will need to obtain permission directly from the copyright holder. To view a copy of this licence, visit http://creativecommons.org/licenses/by/4.0/.

\section{References}

Adeyanju A, Yu J, Little C, Rooney W, Klein P, Burke J, Tesso T (2016) Sorghum RILs segregating for stay-green QTL and leaf dhurrin content show differential reaction to stalk rot diseases. Crop Sci 56(6):2895. https://doi.org/10.2135/cropsci2015.10.0628 
Araus JL, Cairns JE (2014) Field high-throughput phenotyping: the new crop breeding frontier. Trends Plant Sci 19(1):52-61. https:// doi.org/10.1016/j.tplants.2013.09.008

Arrázola G, SánchezP R, Dicenta NG (2012) Content of the cyanogenic glucoside amygdalin in almond seeds related to the bitterness genotype. Agronomía Colombiana 30(2):260-265

Batz J, Méndez-Dorado MA, Thomasson JA (2016) Imaging for highthroughput phenotyping in energy sorghum. Journal of Imaging 2(1):4. https://doi.org/10.3390/jimaging2010004

Bernays EA, Chapman RF, Leather EM, McCaffery AR, Modder WWD (1977) The relationship of Zonocerus Variegatus (L.) (Acridoidea: Pyrgomorphidae) with cassava (Manihot Esculenta). Bull Entomol Res 67(3):391-404. https://doi.org/10.1017/S0007 485300011202

Blomstedt CK, Gleadow RM, O’Donnell N, Naur P, Jensen K, Laursen T, Olsen CE, Stuart P, Hamill JD, Møller BL, Neale AD (2012) A combined biochemical screen and TILLING approach identifies mutations in Sorghum bicolor L. Moench resulting in acyanogenic forage production: acyanogenic forage sorghum plants. Plant Biotechnol J 10(1):54-66. https://doi.org/10.1111/j.1467-7652.2011. 00646.x

Blomstedt CK, Rosati VC, Møller BL, Gleadow R (2018) Counting the costs: nitrogen partitioning in sorghum mutants. Funct Plant Biol 45(7):705. https://doi.org/10.1071/FP17227

Burke JJ, Chen J, Burow G, Mechref Y, Rosenow D, Payton P, Xin Z, Hayes CM (2013) Leaf dhurrin content is a quantitative measure of the level of pre- and postflowering drought tolerance in sorghum. Crop Sci. https://doi.org/10.2135/cropsci2012.09.0520

Busk PK, Moller BL (2002) Dhurrin synthesis in sorghum is regulated at the transcriptional level and induced by nitrogen fertilization in older plants. Plant Physiol 129(3):1222-1231. https://doi.org/ 10.1104/pp.000687

Chormule A, Sharanabasappa D, Kalleshwaraswamy CM, Asokan R (2019) First report of the fall armyworm Spodoptera frugiperda JE Smith Lepidoptera Noctuidae on sugarcane and other crops from Maharashtra India. J Entomol Zool Stud 7(1):114-117

Conn EE (1981) Cyanogenic glycosides. In: Conn EE (ed) Secondary plant products. Elsevier, Amsterdam, pp 479-500

Cooper G, Swain T (1976) Cyanogenic polymorphism in bracken in relation to herbivore predation. Nature 260:604

Day R, Abrahams P, Bateman M, Beale T, Clottey V, Cock M, Colmenarez Y, Corniani N, Early R, Godwin J, Gomez J, Moreno PG, Murphy ST, Oppong-Mensah B, Phiri N, Pratt C, Silvestri S, Witt A (2017) Fall armyworm: impacts and implications for Africa. Outlooks Pest Manag 28(5):196-201. https://doi.org/10. 1564/v28_oct_02

Diawara MM, Wiseman BR, Isenhour DJ, Lovell GR (1990) Resistance to fall armyworm in converted sorghums. Fla Entomol 73(1):111. https://doi.org/10.2307/3495333

Dowd PF, Sattler SE (2015) Helicoverpa zea (Lepidoptera: Noctuidae) and Spodoptera frugiperda (Lepidoptera: Noctuidae) responses to Sorghum bicolor (Poales: Poaceae) tissues from lowered lignin lines. J Insect Sci. https://doi.org/10.1093/jisesa/ieu162

Feigl F, Anger V (1966) Replacement of Benzidine by copper ethylacetoacetate and tetra base as spot-test reagent for hydrogen cyanide and cyanogen. Analyst 91(1081):282. https://doi.org/10.1039/ an9669100282

Gleadow RM, Møller BL (2014) Cyanogenic glycosides: synthesis, physiology, and phenotypic plasticity. Annu Rev Plant Biol 65(1):155-185. https://doi.org/10.1146/annurev-arpla nt-050213-040027

Gleadow RM, Woodrow IE (2002) Constraints on effectiveness of cyanogenic glycosides in herbivore defense. J Chem Ecol 13:1301-1313

Goergen G, Kumar PL, Sankung SB, Togola A, Tamò M (2016) First report of outbreaks of the fall armyworm Spodoptera frugiperda
(J E Smith) (Lepidoptera, Noctuidae), a new alien invasive pest in West and Central Africa. PLoS ONE 11(10):e0165632. https:// doi.org/10.1371/journal.pone.0165632

Gruss SM, Tuinstra MR (2021) Seedling growth and fall armyworm feeding preference influenced by dhurrin production in sorghum. Purdue Univ Res Repository. https://doi.org/10.4231/3PQE-NP07

Hairmansis A, Berger B, Tester M, Roy SJ (2014) Image-based phenotyping for non-destructive screening of different salinity tolerance traits in rice. Rice 7(1):16. https://doi.org/10.1186/ s12284-014-0016-3

Halkier BA, Moller BL (1989) Biosynthesis of the cyanogenic glucoside dhurrin in seedlings of Sorghum bicolor (L.) moench and partial purification of the enzyme system involved. Plant Physiol 90(4):1552-1559. https://doi.org/10.1104/pp.90.4.1552

Halkier BA, Lykkesfeldt J, Moller BL (1991) 2-nitro-3-(p-Hydroxyphenyl)Propionate and Aci-1-Nitro-2-(p-Hydroxyphenyl) Ethane, Two Intermediates in the Biosynthesis of the Cyanogenic Glucoside Dhurrin in Sorghum bicolor (L.) Moench I PNAS. PNAS 88(2):487-491. https://doi.org/10.1073/pnas. 88.2.487

Harms CL, Tucker BB (1973) Influence of nitrogen fertilization and other factors on yield, prussic acid, nitrate, and total nitrogen concentrations of sudangarss cultivars 1. Agronomy J 65(1):21-26. https://doi.org/10.2134/agronj1973.00021962006500010007x

Hayes CM, Weers BD, Thakran M, Burow G, Xin Z, Emendack Y, Burke JJ, Rooney WL, Mullet JE (2016) Discovery of a dhurrin QTL in sorghum: co-localization of dhurrin biosynthesis and a novel stay-green QTL. Crop Sci 56(1):104. https://doi.org/10. 2135/cropsci2015.06.0379

Hosël W, Conn EE (1982) The aglycone specificity of plant beta glycosidases.Pdf. TIBS 7:219-221

Jones DA (1998) Why are so many food plants cyanogenic? Phytochemistry 47(2):155-162. https://doi.org/10.1016/S00319422(97)00425-1

Krothapalli K, Buescher EM, Li X, Brown E, Chapple C, Dilkes BP, Tuinstra MR (2013) Forward genetics by genome sequencing reveals that rapid cyanide release deters insect herbivory of Sorghum bicolor. Genetics 195(2):309-318. https://doi.org/10.1534/ genetics.113.149567

Masjedi A, Crawford MM, Carpenter NR, Tuinstra MR (2020) Multi-temporal predictive modelling of sorghum biomass using UAV-based hyperspectral and LiDAR data. Remote Sensing 12(21):3587. https://doi.org/10.3390/rs12213587

Miller F (1978) Proposal for release and increase ATx622, BTx622, ATx623, ВТх623, ATx624, BTx624. TAES form 96-72. Seed release committee. Texas Agric. Exp. Stn., College Station

Montini L, Crocoll C, Gleadow RM, Motawia MS, Janfelt C, Bjarnholt N (2020) Matrix-assisted laser desorption/ionization-mass spectrometry imaging of metabolites during sorghum germination. Plant Physiol 183(3):925-942. https://doi.org/10.1104/pp. 19.01357

Neilson EH, Edwards AM, Blomstedt CK, Berger B, Møller BL, Gleadow RM (2015) Utilization of a high-throughput shoot imaging system to examine the dynamic phenotypic responses of a $\mathrm{C} 4$ cereal crop plant to nitrogen and water deficiency over time. J Exp Bot 66(7):1817-1832. https://doi.org/10.1093/jxb/eru526

O'Donnell NH, Møller BL, Neale AD, Hamill JD, Blomstedt CK, Gleadow RM (2013) Effects of PEG-induced osmotic stress on growth and dhurrin levels of forage sorghum. Plant Physiol Biochem 73:83-92. https://doi.org/10.1016/j.plaphy.2013.09.001

Oliver AL, Pedersen JF, Grant RJ, Klopfenstein TJ, Jose HD (2005) Comparative effects of the sorghum bmr- 6 and bmr- 12 genes: II. Grain yield, stover yield, and stover quality in grain sorghum. Crop Sci 45:2240-2245

Patton C, Ranney T, Burton J, Malgenbach J (1997) Natural pest resistance of Prunus Taxa to feeding by adult Japanese beetles: role of 
endogenous allelochemicals in host plant resistance. J Am Soc Horticulture Sci. https://doi.org/10.21273/JASHS.122.5.668

Pentzold S, Zagrobelny M, Bjarnholt N, Kroymann J, Vogel H, Olsen CE, Møller BL, Bak S (2015) Metabolism, excretion and avoidance of cyanogenic glucosides in insects with different feeding specialisations. Insect Biochem Mol Biol 66:119-128. https://doi. org/10.1016/j.ibmb.2015.10.004

Porter KS, Axtell JD, Lechtenberg VL, Colenbrander VF (1978) Phenotype, fiber composition, and in vitro dry matter disappearance of chemically induced brown midrib (Bmr) mutants of sorghum1. Crop Sci. https://doi.org/10.2135/cropsci1978.0011183X0018000 20002x

Price NR (1985) The mode of action of fumigants. J Stored Prod Res 21(4):157-164. https://doi.org/10.1016/0022-474X(85)90010-4

Rosati VC, Blomstedt CK, Møller BL, Garnett T, Gleadow R (2019) The interplay between water limitation, dhurrin, and nitrate in the low-cyanogenic sorghum mutant adult cyanide deficient class 1 . Front Plant Sci 10:1458. https://doi.org/10.3389/fpls.2019.01458

Sohail MN, Blomstedt CK, Gleadow RM (2020) Allocation of resources to cyanogenic glucosides does not incur a growth sacrifice in Sorghum bicolor (L.) moench. Plants 9(12):1791. https:// doi.org/10.3390/plants9121791

Sørensen M, Neilson EH, Møller BL (2018) Oximes: unrecognized chameleons in general and specialized plant metabolism. Mol Plant 11(1):95-117

Sparks AN (1979) A review of the biology of the fall armyworm. Fla Entomol 62(2):82. https://doi.org/10.2307/3494083

Strickland G, Richards C, Zhang H, Step DL (2017) Prussic acid poisoning. Oklahoma State University, Stillwater

Tattersall DB, Bak S, Jones PR, Olsen CE, Nielsen JK, Hansen ML, Høj PB, Møller BL (2001) Resistance to an herbivore through engineered cyanogenic glucoside synthesis. Science 293(5536):1826-1828. https://doi.org/10.1126/science.1062249

Thapa S, Zhu F, Walia H, Yu H, Ge Y (2018) A novel LiDAR-based instrument for high-throughput, 3D measurement of morphological traits in maize and sorghum. Sensors 18(4):1187. https://doi. org/10.3390/s18041187

Tuinstra MR, Krothapalli K, Dilkes B, Buescher E (2016) Purdue Research Foundation. 2016. Genetic mutations that disrupt dhurrin production in sorghum. U.S. Patent 9,512,437.
Varoquaux N, Cole B, Gao C, Pierroz G, Baker CR, Patel D, Madera M, Jeffers T, Hollingsworth J, Sievert J, Yoshinaga Y, Owiti JA, Singan VR, DeGraaf S, Xu L, Blow MJ, Harrison MJ, Visel A, Jansson C, Niyogi KK, Hutmacher R, Coleman-Derr D, O'Malley RC, Taylor JW, Dahlberg J, Vogel JP, Lemaux PG, Purdom E (2019) Transcriptomic analysis of field-droughted sorghum from seedling to maturity reveals biotic and metabolic responses". Proc Natl Acad Sci 116(52):27124-27132. https://doi.org/10.1073/ pnas. 1907500116

Way JL (1984) Cyanide intoxication and its mechanism of antagonism. Annual Review of Pharmalogical Toxicology 24:451-481

Wiseman BR, Gourley L (1982) Fall armyworm (Lepidoptera: Noctuidae): infestation procedures and sorghum resistance evaluations. J Econ Entomol 75(6):1048-1051. https://doi.org/10.1093/jee/ 75.6 .1048

Wiseman BR, Widstrom NW (1980) Comparison of methods of infesting whorl-stage corn with fall armyworm larvae123. J Econ Entomol 73(3):440-442. https://doi.org/10.1093/jee/73.3.440

Wittstock U, Gershenzon J (2002) Constitutive plant toxins and their role in defense against herbivores and pathogens. Curr Opin Plant Biol 5(4):300-307. https://doi.org/10.1016/S1369-5266(02) 00264-9

Zagrobelny M, Bak S, Rasmussen AV, Jørgensen B, Naumann CM, Møller BL (2004) Cyanogenic glucosides and plant-insect interactions. Phytochemistry 65(3):293-306. https://doi.org/10.1016/j. phytochem.2003.10.016

Zhu-Salzman K (2004) Transcriptional regulation of sorghum defense determinants against a phloem-feeding aphid. Plant Physiol 134(1):420-431. https://doi.org/10.1104/pp.103.028324

Publisher's Note Springer Nature remains neutral with regard to jurisdictional claims in published maps and institutional affiliations. 